ARTIGO

\title{
A figura do "amigo crítico" no desenvolvimento de culturas de autoavaliação e melhoria de escolas
}

Carlinda Leite ${ }^{a}$ Paulo Marinho ${ }^{b}$

\section{Resumo}

Recorrendo ao conceito de "amigo crítico", foi realizado um estudo que teve por objetivos identificar e caracterizar a importância que é atribuída à figura do "amigo crítico" como agente promotor de melhoria escolar. Os dados foram recolhidos em três escolas de Educação Básica envolvidas em um projeto de autoavaliação, apoiado por um assessor externo, por meio de entrevistas semiestruturadas aos gestores e de aplicação de um questionário aos elementos das comissões de autoavaliação. A análise de conteúdo das respostas aponta para um reconhecimento da ação do "amigo crítico", nomeadamente por trazer uma visão crítica das situações e por promover oportunidades de refletir e de debater decisões que apoiam mudanças. O estudo permitiu concluir que as assessorias desenvolvidas na lógica do "amigo crítico" podem fortalecer culturas de autoavaliação de escolas geradoras de melhorias e oportunidades de construção de comunidades de aprendizagem transformacionais.

Palavras-chave: Amigo crítico. Assessoria externa. Autoavaliação de escolas. Melhoria. Comunidades de aprendizagem transformacionais.

\section{Introdução}

No quadro dos desafios que são colocados às instituições escolares, tem sido reconhecida a importância de assessorias externas (BOLÍVAR, 2007; FLETCHER; CHRÓINÍN; O'SULLIVAN, 2016; HERRERA; CANCINO, 2018; HARRIS, 2000; KIEWKOR; WONGWANICH; PIROMSOMBAT, 2014; LEITE, 2002; SEGÓVIA, 2010). Nos argumentos apresentados são referidas oportunidades de

\footnotetext{
a Centro de Investigação e Intervenção Educativas, Faculdade de Psicologia e de Ciências da Educação, Universidade do Porto, Porto, Portugal.

b Centro de Investigação e Intervenção Educativas, Faculdade de Psicologia e de Ciências da Educação, Universidade do Porto, Porto, Portugal.
} 
promover melhorias, quer nas formas de organização e gestão escolar, quer nos projetos educativos, quer, ainda, no desenvolvimento profissional dos professores. Contudo, a par desta posição positiva, tem também sido alertado que esses processos de dependências externas remetem, muitas vezes, a instituição escolar e os seus agentes apenas para o cumprimento do que é por outros prescrito, afastando do poder de análise e de decisão aqueles que no quotidiano escolar atuam (TOWSEND, 2011). De fato, as assessorias externas são por vezes concretizadas por modelos de natureza intervencionista, em que os saberes que esses peritos possuem são mobilizados na forma de aconselhamento, mesmo que de forma difusa, no seio da comunidade ou do grupo. Em outros casos, os peritos, embora recorrendo aos seus saberes especializados, não os mobilizam para aconselhamento, e muito menos para a prescrição, mas, sim, como contributo para o aprofundamento de uma reflexão e de um debate que apoiem a tomada de decisões pelos próprios agentes educativos escolares. É neste sentido que Swaffield (2005) refere que o conceito de "amigo crítico", ou do que ele designa de amizade crítica, é uma abordagem multifacetada que pode trazer vantagens no apoio a processos de gestão escolar e na construção e transformação de comunidades profissionais de aprendizagem.

No quadro do reconhecimento de que o papel do "amigo crítico" pode assumir várias lógicas e sentidos, apoiamo-nos em Villalobos (2014) quando sinaliza o conceito como sendo merecedor de constituir um foco de investigações mais aprofundadas, especificamente, em contextos de implementação de processos de autoavaliação de escolas (O’BRIEN et al., 2017). É neste sentido, e corroborando ainda Villalobos (2014), que consideramos importante investigar o papel do "amigo crítico" do ponto de vista das práticas que ocorrem ao nível da escola, e particularmente averiguando o que dele pensam os gestores escolares e os professores, isto é, os que vivem os quotidianos escolares.

É tendo por referência esta problemática que este artigo dá conta de um estudo que teve como objetivos identificar e caracterizar a importância que é atribuída à figura do "amigo crítico", como agente promotor de melhoria escolar, por equipas gestoras de escolas e comissões de autoavaliação escolar (Caave). O estudo organizou-se para responder às seguintes perguntas de investigação: Que importância é atribuída à existência de um "amigo crítico" na assessoria externa a escolas? Que papéis lhe são atribuídos e solicitados na sua relação com uma cultura de autoavaliação orientada para a melhoria da escola?

Na sua estrutura, o artigo caracteriza o conceito de "amigo crítico" que serviu de grelha de análise ao estudo, dá conta do contexto da pesquisa, do procedimento metodológico e dos dados recolhidos e, apoiando-se nesse conceito, tece conclusões 
que ampliam o conhecimento sobre efeitos de uma assessoria externa assente na lógica deste conceito.

\section{O conceito de "amigo crítico" na sua relação com processos de autoavaliação escolares orientados para a melhoria}

A designação de "amigo crítico" e o seu papel no apoio a processos de gestão orientados para a melhoria do funcionamento das escolas, embora considerado recente (VILLALOBOS, 2014), circula no vocabulário acadêmico, há alguns anos, sendo atribuído a Desmond Nuttall a sua utilização, no final dos anos 1970, em contexto de autoavaliação (HELLER, 1988). Mounteford (1988) faz referência à designação critical friends relativamente a um grupo de diretores de escolas inglesas que decidiram fazer um círculo de amigos críticos, tendo como intenção a avaliação e consequente melhoria das suas próprias escolas. Outros autores referem que a emergência do conceito de "amigo crítico" assenta numa relação de "amizade crítica com a escola" (BETLEM; CLARY; JONES, 2019; FLETCHER; CHRÓINÍN; O'SULLIVAN, 2016; LEITE, 2002; WRIGHT; ADAM, 2015), embora considerem que o sentido do termo amizade não se adequa ao seu uso generalizado e às suposições que ele pode suportar no cotidiano das relações interpessoais do foro privativo (GIBBS; ANGELIDES, 2008). Corroborando Aquino (2014), poderemos compreender esse conceito de amizade que está associado ao papel do "amigo crítico" como uma postura de apoio concretizada pelo conhecimento, pelo estudo e pela investigação dentro de uma perspetiva de "amizade intelectual e pedagógica". Neste sentido, é essa amizade que potencia uma crítica fora da dicotomia tradicional e do conflito negativo, pois ela é construída num processo de confiança que promove e desenvolve reflexões e críticas construtivas.

Analisando a expressão "amigo crítico", ela encerra dimensões aparentemente contraditórias entre os dois termos, amigo e crítico, principalmente porque a existência de crítica frequentemente transporta em si conotações negativas, levando a compreender o termo de forma negativa e a criar uma relação hierárquica entre amizade e crítica. No entanto, a componente crítica não implica que ela seja negativa; exige, sim, a capacidade de se afastar da situação particular e observá-la através de diferentes lentes (VILLALOBOS, 2014) para que consiga interpretá-la com a isenção que uma análise rigorosa exige. A par desta postura, exige também, para que essa análise seja aceite, que exista confiança e amizade. Como concluiu Leite (2002), o papel de "amigo crítico" só pode ser adequadamente exercido se a escola e os seus agentes perspetivarem a assessoria externa na lógica de uma amizade crítica, isto é, de alguém com quem se está disposto a partilhar êxitos, 
mas também receios e dúvidas. É nessa plataforma de confiança, que o "amigo crítico" está bem posicionado para colocar questões e interrogações que gerem um aprofundamento da análise das situações. Ao mesmo tempo, ao criar um clima propício à reflexão e à sustentação dos processos de análise, pode contribuir para que o grupo disponha de dados analisados através de múltiplos olhares e de um ambiente disponível à aceitação da crítica feita enquanto amigo (COSTA; KALLICK, 1993) - um amigo que oferece críticas à prática (WACHOB, 2011).

Em síntese, o conceito de "amigo crítico" transporta-nos para alguém que usa positivamente os sentidos de amigo e de crítico, isto é, de alguém que, beneficiando da confiança que lhe é reconhecida, potencia ambientes desafiadores e que abrem possibilidades para um diálogo aprofundado (NILSON; WENNERGREN; SJÖBERG, 2018) potenciador de processos de mudança organizacional. É neste sentido que César (2007), em estudo que recorreu a um trabalho colaborativo entre acadêmicos, professores e estudantes, reconheceu a importância dos acadêmicos atuarem no sentido que estamos a atribuir à figura do "amigo crítico". Nesta atuação, os acadêmicos transportam "para o grupo e para a análise uma visão distanciada, mas ampla e comprometida das situações e um permanente questionamento dos aspetos em jogo [...]" (LEITE, 2002, p. 97), ou seja, trazem para o grupo pontos de vista alternativos que ajudam a ver de novo aquilo que é familiar. É igualmente neste sentido que MacBeath (2005) aponta, como competências chave do "amigo crítico" ser um conselheiro científico, organizador, motivador, facilitador, trazendo para o grupo também uma visão externa.

Outro aspeto a realçar quando se pensa na existência de assessorias desenvolvidas na lógica do "amigo crítico" são as competências exigidas. Swaffield (2006) refere que a figura de "amigo crítico" exige o domínio de competências relacionadas com saber ouvir, observar, questionar, gerir conflitos e mobilizar equipas apoiadas em trabalho colaborativo. A par destas competências, refere ainda este mesmo autor a importância de possuir qualidades, tais como: respeito, empatia, autenticidade, confiança, otimismo, sensibilidade, perceção, consideração e compromisso. É neste sentido que situamos a figura do "amigo crítico" dentro de uma natureza dual, perspetivada na ideia de MacBeath (1999) quando sustentou que o "amigo crítico" entra na escola primeiro como amigo, na intenção de apoiar, e depois de ter estabelecido e consolidado o relacionamento, assume o papel de crítico. O "amigo crítico" surge como agente que desenvolve uma relação de confiança com a escola e com os seus membros por meio da escuta e também da observação, no sentido de os apoiar na construção dos seus próprios caminhos de mudança e sempre orientados para a melhoria. É neste sentido que poderá também funcionar como um apoio às lideranças (HERRERA; CANCINO, 2018). 
É no âmbito desta meta que Butler et al. (2011) consideram que iniciativas de mudança, nas comunidades escolares, justificam o envolvimento de assessorias capazes de proporcionar esse apoio. É nesse apoio que o "amigo crítico" é reconhecido como agente promotor da construção coletiva de mudanças orientadas para a melhoria da organização escolar e das práticas que nela ocorrem. Como é sustentado por Bolívar (2014), o apoio a processos de autoavaliação fundados na procura de uma melhoria que não se baseie exclusivamente nos resultados acadêmicos, implica a construção de comunidades de aprendizagem comprometidas com essa intenção de melhoria e que, por isso, tem efeitos no desempenho escolar.

Na concepção que lhe estamos a atribuir, o "amigo crítico" desenvolve um trabalho facilitador de mudanças, orientadas por esta ideia da melhoria organizacional e da ação profissional, apoiadas por processos de autoavaliação (MACBEATH, 2005; O'BRIEN; MCNAMARA; O'HARA, 2014; O'BRIEN et al., 2017) construídos por comunidades escolares.

Centrando a atenção no papel do "amigo crítico" nos processos de autoavaliação de escolas, alguns estudos têm concluído que ele constitui uma mais-valia por proporcionar um olhar exterior à organização que, acompanhada de características inerentes a uma amizade crítica, confere mais objetividade e validade a esses processos de avaliação (SAMPAIO; LEITE, 2016).

Como a própria expressão indicia, um processo de autoavaliação escolar implica a participação de elementos da instituição em um trabalho de colaboração inerente a comunidades de aprendizagem (KILPATRICK; BARRETT; JONES, 2003). É neste processo que as oportunidades criadas por um trabalho em parceria, de gestores escolares e professores, com um "amigo crítico" que os faça refletir criticamente sobre as suas práticas, ao mesmo tempo que fornece informações complementares que apoiem novas práticas (BASKERVILLE; GOLDBLATT, 2009), potencia um empoderamento (KIEWKOR; WONGWANICH; PIROMSOMBAT, 2014) inerente a uma liderança transformacional (BOLÍVAR, 2003; BARBIERI; FREITAS; MARINHO, 2018). Trata-se, pois, de um apoio baseado numa liderança distribuída (HARGREAVES; FINK, 2006) que leva os outros a mudarem voluntariamente as suas ações em função de projetos comuns. São estas situações que promovem a existência de comunidades de aprendizagem transformacionais (NORTHOUSE, 2016), coletivamente comprometidas em melhorias que promovem justiça social (HOFMAN; DIJKSTRA; HOFMAN, 2009; MCARTHUR, 2019; SAMPAIO; LEITE, 2017). 
Nestes ambientes fundados no comprometimento coletivo, os processos de feedback sobre a organização e as práticas escolares ocorrem no que Wachob (2011) designa por círculos de amizade crítica em que o "amigo crítico" promove ambientes de colaboração entre professores e gestores, sempre orientados para a sua melhoria.

Como se depreende, nesta concepção, as práticas já não correspondem a um único espaço privativo, apesar de pessoais; elas são focos de comunicação entre pares, onde os insucessos e as incertezas são compartilhados e discutidos abertamente e onde a crítica não é negligenciada. Pelo contrário, a crítica constitui a norma e a base para a reflexão. É neste contexto que os professores podem ter uma oportunidade de construir elos fortes de relação colegial e quebrar as barreiras do individualismo e trabalhar estreitamente em conjunto e usufruir de uma aprendizagem enriquecedora entre pares.

Na posição que assumimos, consideramos que as relações de amizade crítica, desenvolvidas por um assessor externo que atue na lógica de "amigo crítico", podem promover um desenvolvimento profissional docente e culturas de mudança orientadas para a melhoria das situações escolares (FLETCHER; CHRÓINÍN; O'SULLIVAN, 2016; WRIGHT; ADAM, 2015). Foi tendo estas ideias por referência que foi realizado o estudo que a seguir é apresentado sobre uma intervenção em escolas em que a assessoria a processos de autoavaliação, orientados para a melhoria, desenvolveu-se segundo o conceito de "amigo crítico".

\section{Contexto e procedimentos metodológicos}

A recolha de dados foi realizada durante os anos letivos de 2017 e 2018, em três escolas de Educação Básica da Rede de Ensino Público de um dos Estados do Nordeste brasileiro (Alagoas), que responderam positivamente a um convite da Secretaria Municipal de Educação para se envolverem em um projeto de autoavaliação. A escolha destas escolas obedeceu aos seguintes critérios: escolas com processos de gestão participativa reconhecidos pela comunidade, com um número significativo de recursos humanos efetivos e justificação do interesse em participar no projeto.

Neste artigo, essas escolas são designadas por escola Alfa, Beta e Ômega e têm as seguintes características: i) Escola Alfa, situada em um bairro periférico da capital do Estado, caracterizado por um contexto de vigorosa vulnerabilidade social, tem a modalidade de Ensino Fundamental $\left(1^{\circ}\right.$ ao $5^{\circ}$ ano $)$ e a de Educação de Jovens e Adultos. Funciona em três turnos (matutino, vespertino e noturno), com 799 alunos, duas coordenadoras pedagógicas, 29 professores e 27 funcionários de 
apoio a atividades administrativas; ii) Escola Beta, localizada em um bairro do centro do município da cidade, integra o Ensino Fundamental $\left(1^{\circ}\right.$ ao $5^{\circ}$ ano $)$ e é frequentada por 229 alunos de classe média e baixa. É uma escola organizada em dois turnos (matutino e vespertino) e dispõe de uma coordenadora pedagógica, 18 professores, nove funcionários e cinco estagiários e iii) Escola Ômega, situada nas periferias do município, é do Ensino Fundamental $\left(1^{\circ}\right.$ ao $5^{\circ}$ ano $)$ e funciona em dois turnos (matutino e vespertino). É frequentada por 245 alunos, que vivem em condições de extrema vulnerabilidade social e tem dois coordenadores pedagógicos, nove professores, três estagiários e oito funcionários.

O projeto recorreu a uma assessoria externa, que atuou na lógica do conceito de "amigo crítico". Os dados foram recolhidos por questionários de perguntas abertas às Caave de cada escola e por entrevistas informais (AMADO, 2014) às equipes gestoras (EG). As perguntas do questionário e das entrevistas focaram as seguintes dimensões: importância atribuída à existência de um "amigo crítico" na assessoria externa a escolas; papéis atribuídos e solicitados ao "amigo crítico" no desenvolvimento de uma cultura de autoavaliação orientada para a melhoria da escola. O questionário não passou por um processo de validação, pelo fato de integrar apenas perguntas abertas.

As Caave constituem um colegiado de natureza propositiva, consultiva e deliberativa, formada por membros da escola (professores, alunos e funcionários) e representantes da comunidade educativa (pais e elementos de instituições da comunidade), e são responsáveis pela seleção dos procedimentos de autoavaliação da escola e sua posterior utilização. Estas Caave eram constituídas por 10 a 12 elementos, sendo: Escola Alfa - seis professores, dois alunos, uma Coordenadora Pedagógica, dois Representantes de Pais, um Representante de instituições da comunidade; Escola Beta - cinco professores, uma Coordenadora Pedagógica, um Representante de funcionários, dois Representantes de Pais, um Representante de instituições da comunidade; Escola Ômega - seis professores, dois representantes de funcionários, dois representantes de pais, um líder comunitário.

Tanto as entrevistas informais como as respostas ao questionário foram objeto de um consentimento informado e são anonimizadas. A análise seguiu a técnica de análise de conteúdo (BARDIN, 2008) e permitiu identificar três categorias atribuídas pelos respondentes à ação do "amigo crítico": i) fornece uma visão externa potenciadora da reflexão; ii) facilita a tomada de decisão e da mudança orientada para a melhoria e iii) escuta e fomenta o diálogo. É em função dessas categorias de análise que são apresentados os dados. 


\section{Apresentação e discussão dos dados}

Os dados são apresentados indicando as escolas pelas designações que lhes foram atribuídas e antecedendo essa designação por um EG, se se trata de dados relativos a um gestor escolar, ou de Caave se se trata de resposta de elementos da Comissão de autoavaliação.

\subsection{O "amigo crítico" fornece uma visão externa potenciadora de reflexão}

O olhar externo do "amigo crítico" foi referenciado pelas Caave das escolas na medida em que oferece ao grupo um outro olhar sobre a realidade. Foi afirmado:

Sua visão externa é fundamental, não está com certos vícios da organização [...]. Sua presença é primordial, pois coloca em nós óculos de verdade da nossa realidade e objetividade. [...] Necessitamos de um amigo crítico que, principalmente, conheça a nossa realidade, mas que esteja atrelado a outras realidades e não que não seja uma pessoa só do nosso meio educacional, pois ajuda a ver mais, outras experiências, outros contextos, como está acontecendo [...] (Caave, Ômega).

É de fundamental importância, na medida em que contribui significativamente para que a autoavaliação de fato aconteça. [...] o não ter vínculo com a escola é importante, o que lhe permite autonomia total para exercer seu papel enquanto "amigo crítico"; a crítica é mais assertiva e aceite por todos [...] (Caave, Beta).

Aquela pessoa que tem conhecimento na área de avaliação interna, é próxima à escola, mas não pertence à escola, [...] está vendo "de fora" e pode contribuir lançando desafios e até luz sobre questões fundamentais que precisam ser melhoradas [...]. é uma visão externa que consegue enxergar melhor as nossas limitações, tem um olhar alargado a toda a organização, com ideias e críticas para um melhor desenvolvimento das atividades escolares e ações próprias do processo de autoavaliação (Caave, Alfa).

Como se depreende dos depoimentos, o papel do "amigo crítico" é visto como transportador de uma visão externa que, simultaneamente, é próxima das realidades da escola, mas que não se encontra afetada pelos referenciais culturais organizacionais, isto é, que não está contaminada e poluída “com certos vícios 
da organização" (Caave, Ômega). Neste sentido, transporta para o grupo e para a análise uma visão distanciada, mas ampla e comprometida com as situações (LEITE, 2002), oferecendo pontos de vista alternativos e ajudando a ver de novo aquilo que, quotidianamente, é ofuscado pela familiaridade das rotinas e dos hábitos das culturas organizacionais. Na linha de uma cultura de autoavaliação, a assessoria desenvolvida neste procedimento apoia a instituição escolar e os seus atores a analisarem as situações com que convivem num compromisso de mudanças orientados para uma contínua melhoria. Como foi afirmado, o "amigo crítico" fornece um olhar caleidoscópio e sistémico que "consegue enxergar melhor as $[\ldots]$ limitações $[\ldots]$ para um melhor desenvolvimento das atividades escolares e ações próprias do processo de autoavaliação" (Caave, Alfa). Entende-se assim, que o "amigo crítico", no sentido que lhe estamos a atribuir, contribui para uma leitura da complexidade que acompanha os contextos de ação, isto é, apoia e aprofunda processos de reflexão.

É nesse sentido que a gestão da escola Beta refere:

[...] distanciado e próximo nos faz ver aquilo que todos os dias está à nossa frente, coisas que não enxergamos ou não queremos ver, por comodismo, porque isso pode trazer muito incomodo, mal-estar, incompreensões por parte dos professores; é muito complicado, mas com o amigo crítico é diferente, ele aponta de forma suave, mas tão sustentado nos dados da nossa realidade que por vezes a realidade até dói. Eu costumo dizer - ele abraça e a seguir sopra. Isso ajuda imenso a gestão e assim as pessoas começam a entender que ninguém está contra ninguém, apenas queremos melhorar. $\mathrm{O}$ amigo crítico tem sido fundamental para tudo isto, para que se consiga mobilizar e motivar todos para um processo de melhoria. Mesmo assim não tem sido fácil quebrar a cultura instituída - deixar tudo como está, como sempre foi, mas esse é o caminho (EGbeta).

A perceção deste gestor escolar remete-nos à ideia de que o "amigo crítico" entra na escola numa situação de amigo e, posteriormente, dentro do quadro dessa amizade, assume a dimensão de criticidade sobre a prática (WACHOB, 2011), como é referido, é aquele que "abraça e sopra". Nessa mesma perceção pode-se constatar também uma potente presença do "amigo crítico" como um mediador educacional, neste caso, entre a equipe de gestão e os professores. A mediação é reconhecida como um processo que congrega uma visão distanciada da vivência das situações problemáticas e próxima no compromisso de promover uma prática reflexiva sobre essas mesmas situações. Neste sentido, oferece oportunidades 
de desconstrução e construção de significados das realidades, congregando os vários agentes educativos num objetivo comum, no qual as "pessoas começam a entender que ninguém está contra ninguém, apenas [para] melhorar" (EGbeta). Esta opinião apoia a ideia de que o "amigo crítico" constitui um recurso para uma "gestão promissora e transformadora - que consegue mobilizar a escola para um processo de mudança e de melhoria, por meio de processos de participação ativa e de motivação de todos seus agentes educativos" (BARBIERI; FREITAS; MARINHO, 2018, p. 92). É neste contexto, que "amigo crítico" é também considerado um agente facilitador de tomada de decisão e de mudança organizacional.

\subsection{O "amigo crítico" como agente facilitador de tomada de decisão e de mudança orientada para a melhoria}

Nas suas respostas, as Caave foram perentórias em afirmar que a assessoria externa, realizada na ótica da figura do "amigo crítico", é importante para o desenvolvimento dos processos de autoavaliação. Afirmaram:

[...] trata-se de uma pessoa que não está envolvida diretamente na equipe de elaboração do projeto, porém detém conhecimentos necessários para promover um novo repensar, debates e discussões que favoreçam a tomada de decisões e mudanças de práxis e paradigmas $[\ldots]$ (Caave, Beta).

O amigo crítico é essencial, pois ajuda-nos no projeto de autoavaliação e provoca mudanças para a melhoria do desenvolvimento do projeto; leva-nos a estudar, aprofundar conhecimentos, traçar ações estratégicas para a resolução de problemas [...] (Caave, Ômega).

É muito importante porque baseado nos dados da escola, ele vai nos favorecer com sua visão crítica nos ajudando a perceber os caminhos que devemos seguir; através de diálogo e questionamentos, propondo-nos sugestões de mudanças para a melhoria contínua e caminhando para a excelência (Caave, Alfa).

Como se depreende destes excertos, o assessor externo, ao funcionar como "amigo crítico", apoiou o desenvolvimento de processos de autoavaliação de escolas, promovendo um debate e uma discussão mobilizadores da escola e de seus agentes para a tomada de decisões e de mudanças fundamentadas, isto é, potencializou a autoavaliação institucional como um mecanismo para a melhoria (MACBEATH, 2005; O'BRIEN, et al., 2017; O'BRIEN; MCNAMARA; 
O'HARA, 2014) As características apontadas ao "amigo crítico", em situação de assessoria ao desenvolvimento da autoavaliação escolar, vão ao encontro do que foi considerado por Leite (2002): "um facilitador na tomada de decisões", cuja "função é ajudar a escola e os seus agentes a refletirem as situações para que tomem as suas próprias decisões" (LEITE, 2002, p. 97).

É dentro deste quadro de facilitador de tomada de decisões e mudanças que o "amigo crítico" apoia também a comunidade escolar a assumir compromissos de uma intervenção que possa sustentar planos de melhoria concretos e efetivos. Este argumento é evidenciado pelas seguintes respostas:

É aquela pessoa de quem a escola tem apoio no momento de busca por metodologia, por respostas, por orientações lógicas, objetivas e concretas $[\ldots]$ (Caave, Alfa).

Uma pessoa com uma experiência profissional de formador de professores e com grandes conhecimentos em métodos de pesquisa-ação. Tem um papel muito importante para auxiliar no diagnóstico da escola, ajudando na identificação dos pontos fortes e fracos (Caave, Beta).

É um amigo que ajuda a escola a se autoavaliar apontando possíveis fraquezas e direcionamentos que a mesma deve assumir em seu plano de intervenção. É essencial para fortalecer o grupo com conhecimento, através de formação continuada no chão da escola, contextualizada nos problemas e necessidades reais da escola. Promove e fortalece participação na construção de ferramentas para que o grupo possa elaborar e aplicar um plano de melhoria construído por todos, da base para o topo, onde todos participamos e aprendemos (Caave, Ômega).

Pelos discursos apresentados, depreende-se que o "amigo crítico" é reconhecido no seu papel de conselheiro científico (MACBEATH, 2005), sendo alguém que confere objetividade e validade aos processos de autoavaliação (VILLALOBOS, 2014), atitude importante para o desenvolvimento de mudanças e de transformações na escola. Como foi referido, o "amigo crítico" é "essencial para fortalecer o grupo com conhecimento, através de formação [...] contextualizada nos prolemas e necessidades reais da escola [...] e participação na construção de ferramentas" (Caave; Ômega) necessárias para a concretização da autoavaliação institucional.

Como tem sido afirmado, o "amigo crítico", ao recorrer a estratégias em que os professores trabalham em parceria, contribui para o aperfeiçoamento profissional 
de cada um (BASKERVILLE; GOLDBLATT, 2009; FLETCHER; CHRÓINÍN; O'SULLIVAN, 2016). Trata-se de um aperfeiçoamento ancorado em comunidades de aprendizagem e em que, como foi referido, "todos participamos e aprendemos" (Caave, Ômega) com todos. São estas comunidades de aprendizagem que se orientam para uma mudança e uma transformação (NORTHOUSE, 2016) orientada para a melhoria contínua.

Neste mesmo quadro argumentativo sobre o "amigo crítico", a gestão da escola Beta refere:

Uma pessoa que olha para mim com uma postura realista. Alguém que me fala claramente e sem negativismo o que eu preciso melhorar. É muito conhecedor, mas humilde e sabe muito bem lidar com o público, respeita, tem um compromisso enorme com a escola, incentiva, orienta e acompanha de fato a equipe escolar (EGbeta).

Este testemunho demonstra a aceitação da assessoria externa dentro de uma relação de uma amizade crítica com a escola e os seus agentes (BETLEM; CLARY; JONES, 2019; FLETCHER; CHRÓINÍN; O'SULLIVAN, 2016; WRIGHT; ADAM, 2015), e onde todos são ouvidos e respeitados. Demonstra também que a crítica não implica ser negativa (VILALOBOS, 2014). Estas ideias vão ao encontro do que Leite (2002) reforçou quando refere que o papel efetivo de "amigo crítico" só pode ser adequadamente exercido se a escola e os seus agentes de fato o aceitarem dentro de uma base de amizade crítica - em que todos possam trabalhar com confiança na partilha dos êxitos, mas também dos fracassos e das dúvidas. Esta foi também a opinião dos gestores envolvidos neste projeto:

Nunca tive a oportunidade de viver uma experiência deste tipo de assessoria, é a primeira vez como gestor(a). [...] tem sido uma experiência de parceria mesmo, de estarmos junto, ajudar a enxergar melhor, construir instrumentos, interpretar os dados, organizar [...]. [O amigo crítico é] extramente importante nos processos de autoavaliação (EGalfa).

Já tivemos, em outros projetos, outros assessores, consultores, mas muito diferente, são muito distantes, mandam receitas, desta vez não é receita, é construção e desconstrução constante, instiga, provoca, destabiliza a zona de conforto, está junto e motiva-nos a avançar e ir em frente, fazer melhor o que não está menos bem e levar à excelência o que está bem (EGbeta). 
É um instigador, pesquisador e conhecedor nato que nos tem levado a avançar para a melhoria organizacional [...]. Veste a camisa da escola; em nosso primeiro seminário sobre autoavaliação na escola ficámos muito envolvidos, entusiasmados e mandamos fazer umas camisas com o nome do projeto de autoavaliação, foi mesmo vestir a camisa e o assessor do projeto faz isso mesmo, você sente que ele está com a gente (EGômega).

Neste contexto e sem "receita" (EGBETA), o "amigo crítico" trabalha "com e não por" (LEITE, 2003), "veste a camisa da escola" (EGômega) e promove ações que apoiam a criação de mecanismos que provocam a "[des]construção constante, instiga[ção], provoca[ção], destabiliza[ção] [d]a zona de conforto" (EGbeta) que se refletem em situações de melhoria das escolas, apoiadas em processos de autoavaliação. São esses processos que favorecem um conhecimento sistémico e integrado dos fenómenos educativos e das suas concretizações.

\subsection{O amigo crítico em quem se confia, que escuta e fomenta o diálogo}

Nas características atribuídas à figura do "amigo crítico" em processos de autoavaliação institucionais escolares, foram ainda referenciados aspetos relativos à confiança, ao diálogo e à escuta como potenciadores do empoderamento dos agentes educativos. Foi afirmado:

É uma pessoa na qual se confia, que tem um olhar diferenciado e busca fazer com que se perceba o lado positivo e o negativo de algo que se precise executar. É a pessoa com conhecimento teórico e prático sobre o projeto. $\mathrm{O}$ amigo crítico sabe se portar diante dos componentes da escola e faz nascer um ambiente de confiança e parceria (Caave, Alfa).

No contexto educacional precisamos de um amigo crítico que tenha de fato conhecimento acadêmico, postura dialética e confiança nos envolvidos (na escola). A característica forte desse projeto é a pesquisa, portanto o diálogo e a escuta são importantes e marcantes para termos resultados positivos. É uma pessoa acessível, bom ouvinte, criterioso e que tem conhecimento das necessidades reais da organização escolar, contribuindo para ações de mudanças efetivas (Caave, Ômega). 
Transmite confiança ao grupo pelo conhecimento que tem e pela pessoa séria e sensata que é. Sabe ouvir, sabe indagar, sabe criar dúvidas, cria desafios, elogia, incentiva, mas crítica, uma crítica positiva, ou seja, pela crítica sabe criar dúvidas em todos nós (Caave, Beta).

Depreende-se destes depoimentos que a confiança se assume como base primordial na ação do "amigo crítico", sendo que é por meio desta que é aceite a criticidade sobre o trabalho realizado na escola e pelos seus agentes (COSTA; KALLICK, 1993) e em que são estabelecidas relações mais próximas e profundas de diálogo (NILSON, WENNERGREN, SJÖBERG, 2018). Como se depreende, essas relações, apoiadas também por uma escuta atenta, são essenciais para desenvolver uma comunicação eficaz fundada no respeito e reconhecimento de cada um. São elas também que apoiam a construção de grupos comprometidos com a mudança orientada para a melhoria (FLETCHER; CHRÓINÍN; O'SULLIVAN, 2016; WRIGHT; ADAM, 2015).

A confiança, o diálogo e a escuta do "amigo crítico" são características reconhecidas como importantes para o empoderamento dos sujeitos. São disso exemplo os seguintes depoimentos:

A presença do amigo crítico é de suma importância no projeto de autoavaliação, pois ele tem a responsabilidade de provocar a equipe, orientar e oferecer informações seguras, claras e bem definidas (Caave, Alfa).

O amigo crítico tem vindo a acrescentar conhecimento e aprendizagem aos envolvidos no projeto e motivação, contribuindo para o nosso empoderamento profissional. É uma pessoa que opina, sugere, alerta os erros, elogia e amplia os conhecimentos do grupo. Orienta para alcançarmos objetivos comuns e melhorar (Caave, Ômega).

[...] é extremamente criterioso, na busca pela excelência, além de ter a capacidade de manter o grupo sempre motivado sabendo respeitar a autonomia escolar. É uma pessoa que acompanha e auxilia a equipe escolar em suas ações de autoavaliação, além de ser capaz de impulsionar a construção de uma nova cultura de avaliação (Caave, Beta).

Como os depoimentos mostram, a atuação do "amigo crítico" é valorizada por escutar, respeitar, motivar, ter empatia, assegurar confiança e compromisso 
(SWAFFIELD, 2006; SWAFFIELD; MACBEATH, 2005), isto é, competências que contribuem para o empoderamento dos sujeitos (KIEWKOR; WONGWANICH; PIROMSOMBAT, 2014). Neste caso específico, a assessoria externa a processos de autoavaliação de escolas, realizada na lógica do "amigo crítico", contribuiu também para uma aprendizagem profissional que mobilizou os agentes educativos na procura de uma contínua melhoria da escola e da ação educativa.

Em síntese, na tabela 1, respondendo às perguntas de investigação, esquematizamos a importância que os participantes neste estudo atribuíram à existência de um "amigo crítico" na assessoria a instituições escolares e papéis que lhe são atribuídos e solicitados na sua relação com uma cultura de autoavaliação orientada para a melhoria da escola.

Tabela 1 - Importância e papéis atribuídos à existência de um "amigo crítico" na assessoria

\begin{tabular}{|c|c|}
\hline $\begin{array}{l}\text { Importância do "amigo crítico" e papéis } \\
\text { que lhe são reconhecidos: }\end{array}$ & $\begin{array}{l}\text { Importância do "amigo crítico" no } \\
\text { assessoramento à escola no seu projeto } \\
\text { de autoavaliação: }\end{array}$ \\
\hline 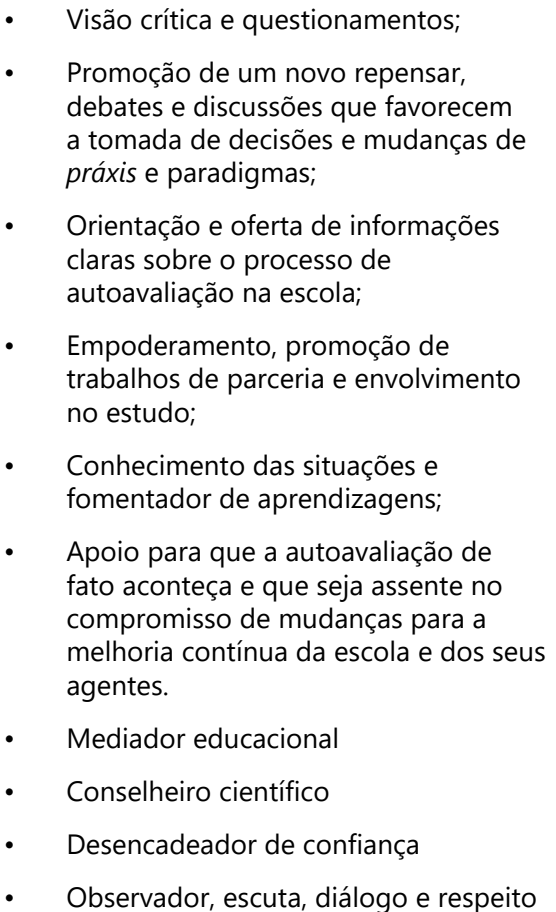 & 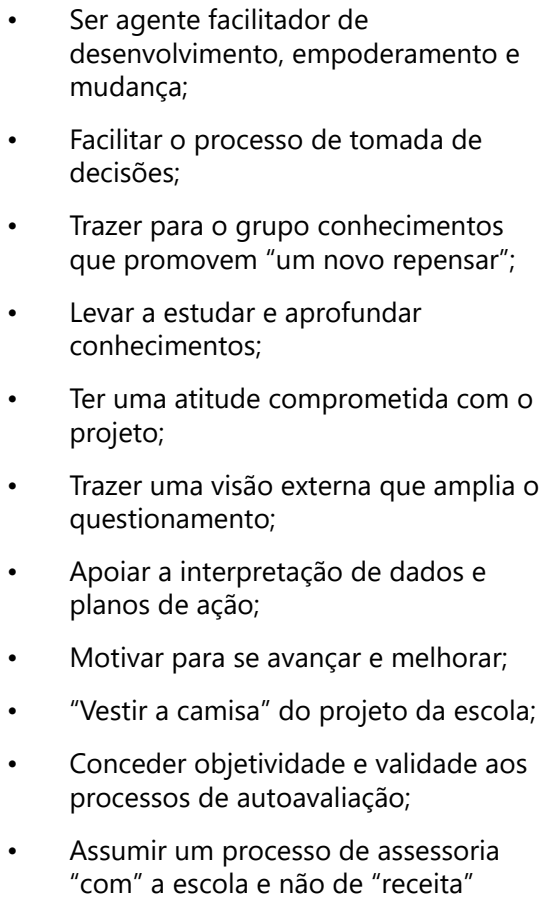 \\
\hline
\end{tabular}

Fonte: Elaboração dos autores, 2019 


\section{Conclusões}

Como o estudo demonstrou, a existência de uma assessoria externa a escolas realizada na ótica do "amigo crítico" é reconhecida como importante pelos papéis que exerce e características que o definem no apoio a tarefas de agentes educativos. $\mathrm{O}$ que foi enunciado pelos gestores e elementos das comissões de avaliação das escolas envolvidas neste estudo permitiu clarificar razões que justificam a importância do "amigo crítico" no assessoramento ao desenvolvimento de culturas de autoavaliação orientadas para a melhoria e ampliar conclusões de outros estudos (BOLÍVAR, 2007; FLETCHER; CHRÓINÍN; O'SULLIVAN, 2016; HARRIS, 2000; KIEWKOR; WONGWANICH; PIROMSOMBAT, 2014; LEITE, 2003; SEGÓVIA, 2010). Os dados recolhidos tornaram evidente as possibilidades das assessorias externas, realizadas no quadro das características atribuídas a um "amigo crítico", poderem contribuir para um desenvolvimento profissional que empodere as instituições e os seus agentes em tomadas de decisão geradoras de mudanças orientadas para a melhoria.

Como o estudo mostrou, as relações de amizade crítica desenvolvidas pelo assessor externo podem proporcionar uma evidente melhoria da aprendizagem profissional docente que contribua para um melhor desempenho profissional, na linha do que foi evidenciado por Fletcher, Chróinín e O’Sullivan (2016). O estudo igualmente mostrou que a figura do "amigo crítico" potenciou a existência de possibilidades de uma "recultura" da escola e da sua comunidade, que se assumiu como uma comunidade de aprendizagem com uma responsabilidade coletiva, comprometida com a construção de processos de melhoria organizacionais e profissionais.

É a partir da interpretação dos dados recolhidos neste estudo que reforçamos que as assessorias externas, desenvolvidas na linha do "amigo crítico", podem favorecer o desenvolvimento de mecanismos internos potenciadores de culturas de autoavaliação institucional e profissional orientadas para a melhoria escolar (O'BRIEN et al., 2017; O'BRIEN; MCNAMARA; O'HARA, 2014), e apoiar a existência de comunidades de aprendizagens transformacionais (NORTHOUSE, 2016). A figura de um "amigo crítico", como também sustentou Villalobos (2014), pode contribuir com uma perspetiva necessária a uma abordagem equilibrada de mudanças e transformações na escola, dentro de um quadro de alto nível de comprometimento, dedicação e confiança no seu conhecimento e apoio. 


\section{The "critical friend" figure in the development of cultures of self-assessment and school improvement}

\section{Abstract}

Based on the concept of "critical friend" it was developed a study with the following objectives: identify and characterize the importance attributed to the "critical friend" as a promoter of school improvement. The data were collected in three basic education schools involved in a self-assessment project, supported by an external advisor, using semi-structured interviews with managers and questionnaires to the self-assessment committees. The answers content analysis points to a recognition of the "critical friend" action, namely by bringing a critical view and questions that promote opportunities for reflection and by debating situations that support decision making for change. The study allows to conclude that the advisement developed in a "critical friend" way can strengthen self-assessment cultures to improve schools and opportunities to develop transformational learning communities.

Keywords: Critical friend. External advisement. School self-assessment. Improvement. Transformational learning communities.

\section{La figura del "amigo crítico" en el desarrollo de las culturas de autoevaluación y mejora de escuelas}

\section{Resumen}

Utilizando el concepto de "amigo crítico" se realizó un estudio que tuvo como objetivo identificar y caracterizar la importancia que se le atribuye a la figura del "amigo crítico" como agente promotor de la mejora escolar. Los datos fueron recolectados en tres escuelas de Educación Básica involucradas en un proyecto de autoevaluación, apoyado por un asesor externo, a través de entrevistas semiestructuradas con gestores y con la aplicación de un cuestionario a los miembros de las comisiones de autoevaluación. El análisis de contenido de las respuestas apunta a un reconocimiento de la acción del "amigo crítico", es decir, para traer una visión crítica de las situaciones y para promover oportunidades para reflexionar y debatir decisiones que apoyen los cambios. El estudio permitió concluir que las consultorías desarrolladas en la lógica del "amigo crítico" pueden fortalecer culturas de autoevaluación en las escuelas que generan mejoras y oportunidades para construir comunidades de aprendizaje transformacionales.

Palabras clave: Amigo crítico. Asesoramiento externo. Autoevaluación de escuelas. Mejora. Comunidades de aprendizaje transformacionales. 


\section{Referências}

AMADO, J. Manual de investigação qualitativa em educação. Coimbra: Imprensa da Universidade de Coimbra, 2014.

AQUINO, J. G. Da autoridade pedagógica à amizade intelectual: uma plataforma para o éthos docente. São Paulo: Cortez, 2014.

BARBIERI, P.; FREITAS, M.; MARINHO, P. Premissas de culturas gestoras na (des)promoção de processos de gestão promissores e transformadores. In: MARINHO, P.; FREITAS, M. (org.). Educação e cultura escolar: focus contemporâneos. Maceió: Edufal, 2018. p. 78-98.

BARDIN, L. Análise de conteúdo. Lisboa: Edições 70, 2008.

BASKERVILLE, D.; GOLDBLATT, H. Learning to be a critical friend: from professional indifference through challenge to unguarded conversations. Cambridge Journal of Education, Cambridge, v. 39, n. 2, p. 205-221, 2009. https://doi.org/10.1080/03057640902902260

BETLEM, E.; CLARY, D.; JONES, M. Mentoring the mentor: professional development through a school-university partnership. Asia-Pacific Journal of Teacher Education, [s. 1.], v. 47, n. 4, p. 327-346, 2019. https://doi.org/10.1080/1359866X.2018.1504280

BOLÍVAR, A. Como melhorar as escolas: estratégias e dinâmicas das políticas educativas. Porto: ASA, 2003.

BOLÍVAR, A. La autoevaluación en la construcción de capacidades de mejora de la escuela como comunidad de aprendizaje profesional. Revista Portuguesa de Investigação Educacional, Porto, n. 14, p. 9-40, 2014. https://doi.org/10.34632/investigacaoeducacional.2014.3398

BOLÍVAR, A. Um olhar actual sobre a mudança educativa: onde situar os esforços de melhoria?. In: LEITE, C.; LOPES, A. (orgs.). Escola, currículo e formação de identidades. Porto: Edições ASA, 2007. p. 13-50.

BUTLER, H. et al. The critical friend: facilitating change and wellbeing in school communities. Victoria: ACER Press, 2011. 
CÉSAR, M. Dialogical identities in students from cultural minorities or students categorised as presenting SEN: how do they shape learning, namely in mathematics?. In: SCTIG GROUP (ed.). 2nd socio-cultural theory in educational research \& practice conference proceedings. Manchester: University of Manchester, 2007.

COSTA, A.; KALLICK, B. Through the lens of a critical friend. Educational Leadership, [s. 1.], v. 51, n. 2, p. 49-51, Jan. 1993.

FLETCHER, T.; CHRÓINÍN, D.; O'SULLIVAN, M. A layered approach to critical friendship as a means to support pedagogical innovation in pre-service teacher education. Studying Teacher Education, [s. 1.], v. 12, n. 3, p. 302-319, ago. 2016. https://doi.org/10.1080/17425964.2016.1228049

GIBBS, P.; ANGELIDES, P. Understanding friendship between critical friends. Improving Schools, [s. 1.], v. 11, n. 3, p. 213-225, Nov. 2008. https://doi.org/10.1177/1365480208097002

HARGREAVES, A.; FINK, D. Redistributed leadership for sustainable professional learning communities. Journal of School Leadership, [s. 1.], v. 16, n. 5, p. 550-565, Sep. 2006. https://doi.org/10.1177/105268460601600507

HARRIS, A. What works in school improvement? Lessons from the field and future directions. Educational Research, [s. 1.], v. 42, n. 1, p. 1-11, 2000. https://doi.org/10.1080/001318800363872

HELLER, H. The advisory service and consultancy. In: GRAY, H. L. (ed.). Management consultancy in schools. London: Cassell, 1988. p. 117-128.

HERRERA, C. I.; CANCINO, V. E. C. Asesoramiento a equipos de gestión y liderazgo educativo desde el abordaje de las competencias funcionales. Ensaio: Avaliação e Políticas Públicas em Educação, Rio de Janeiro, v. 26, n. 101, p. 1220-1239, out./dez. 2018. https://doi.org/10.1590/s0104-40362018002601381

HOFMAN, R.; DIJKSTRA, N.; HOFMAN, A. School self-evaluation and student achievement. School Effectiveness and School Improvement, [s. 1.], v. 20, n. 1, p. 47-68, 2009. https://doi.org/10.1080/09243450802664115

KIEWKOR, S.; WONGWANICH, S.; PIROMSOMBAT, C. Empowerment of teachers through critical friend learning to encourage teaching concepts. Procedia-Social and Behavioral Sciences, [s. 1.], v. 116, p. 4626-4631, Feb. 2014. https://doi.org/10.1016/j.sbspro.2014.01.997 
KILPATRICK, S.; BARRETT, M.; JONES, T. Defining learning communities. Lauceston: University of Tasmania, 2003. Disponível em: https://www.researchgate.net/publication/43527785_Defining_Learning_ Communities. Acesso em: 10 set. 2019.

LEITE, C. A figura do amigo crítico no assessoramento/desenvolvimento de escolas curricularmente inteligentes. In: FERNANDES, M. O particular e o global no virar do milénio: cruzar saberes em educação. Lisboa: Colibri, 2002. p. $95-120$.

LEITE, C. Para uma escola curricularmente inteligente. Porto: Edições ASA, 2003.

MCARTHUR, J. La evaluación: una cuestión de justicia social: persctivas crítica y prácticas adecuadas. Madrid: Narcea, 2019.

MACBEATH, J. Leadership as distributed: a matter of practice. School Leadership \& Management, [s. 1.], v. 25, n. 4, p. 349-366, 2005. https://doi.org/10.1080/13634230500197165

MACBEATH, J. Schools must speak for themselves: the case of school self-evaluation. Routledge: New York, 1999.

MOUNTEFORD, J. The role of critical friends in school evaluation. School Leadership \& Management, [s. 1.], v. 8, n. 3, p. 255-260, 1988. https://doi.org/10.1080/0260136880080302

NILSON, M. H.; WENNERGREN, A. C.; SJÖBERG, U. Tensions in communication: teachers and academic facilitators in a critical friendship. Action Research, [s. 1.], v. 16, n. 1, p. 7-24, 2018. https://doi.org/10.1177/1476750316660365

NORTHOUSE, P. Leadership: theory and practice. 7. ed. Thousand Oaks: Sage, 2016.

O'BRIEN, S. et al. External specialist support for school self-evaluation: Testing a model of support in Irish post-primary schools. Evaluation, London, v. 23, n. 1, p. 61-79, Jan. 2017. https://doi.org/10.1177/1356389016684248

O'BRIEN, S.; MCNAMARA, G.; O'HARA, J. Critical facilitators: external supports for self-evaluation and improvement in schools. Studies in Educational Evaluation, [s. 1.], v. 43, p. 169-177, Dec. 2014. https://doi.org/10.1016/j.stueduc.2014.08.002 
SAMPAIO, M.; LEITE, C. A avaliação externa das escolas e os TEIP na sua relação com a justiça social. Educação, Sociedade \& Culturas, Porto, n. 47, p. 115-136, 2016.

SAMPAIO, M.; LEITE, C. From curricular justice to educational improvement: what is the role of schools' self-evaluation? Improving Schools, [s. 1.], v. 20, n. 1, p. 62-75, Mar. 2017. https://doi.org/10.1177/1365480216688553

SEGÓVIA, J. D. Comprender y redireccionar las prácticas de asesoría. Revista Iberoamericana de Educación. [s. 1.], n. 54, p. 65-83, set./dic. 2010.

SWAFFIELD, S. Critical friends: supporting leadership, improving learning. Improving Schools, v. 7, n. 3, p. 267-78, Mar. 2006. https://doi.org/10.1177/1365480204049340

SWAFFIELD, S.; MACBEATH, J. School self-evaluation and the role of a critical friend. Cambridge Journal of Education, Cambridge, v. 35, n. 2, p. 239-252, June 2005. https://doi.org/10.1080/03057640500147037

TOWSEND, T. Searching high and searching low, searching east and searching west: Looking for trust in teacher education. Journal of Education for Teaching, [s. 1.], v. 37, n. 4, p. 483-499, Nov. 2011. https://doi.org/10.1080/02607476.2011.611017

VILLALOBOS, M. H. The role of the critical friend in leadership and school improvement. Dissertation (Master of Educational Management) Melbourne Graduate School of Education, The University of Melbourne, Melbourne, 2014.

WACHOB. P. Critical friendship circles: the cultural challenge of cool feedback. Professional Development in Education, [s. 1.], v. 37, n. 3, p. 353-372, 2011. https://doi.org/10.1080/19415257.2010.537064

WRIGHT, N.; ADAM, A. The 'critical friend' role in fostering reflective practices and developing staff cohesion: a case study in a new secondary school, New Zealand. School Leadership \& Management, [s. 1.], v. 35, n. 4, p. 441-457, 2015. https://doi.org/10.1080/13632434.2015.1070821 


\section{Informações sobre os autores}

Carlinda Leite: Doutora em Ciências da Educação. Professora Catedrática da Faculdade de Psicologia e de Ciências da Educação da Universidade do Porto e Professora Emérita da mesma universidade. Investigadora sénior no Centro de Investigação e Intervenção Educativas. Presidente da Comissão de Ética da mesma faculdade; Avaliadora da Agência de Avaliação e Acreditação do Ensino Superior e Coordenadora da Comunidade prática de investigação: Currículo, Avaliação, Formação e Tecnologias Educativas. Contato: carlinda@fpce.up.pt

(iD) https://orcid.org/0000-0001-9960-2519

Paulo Marinho: Doutor em Ciências da Educação, com Pós-Doutoramento em Educação Brasileira. Investigador no Centro de Investigação e Intervenção Educativas da Faculdade de Psicologia e de Ciências da Educação da Universidade do Porto. Professor colaborador no Programa de Pós-Graduação em Educação da Universidade Federal de Alagoas, Brasil. Membro da Comunidade prática de investigação: Currículo, Avaliação, Formação e Tecnologias Educativas. Contato: pmtmarinho@fpce.up.pt

(iD) https://orcid.org/0000-0003-4898-2982 